\title{
Where Do IT Staff Position Themselves: A Case Study Exploring Common Ground
}

\author{
Kay Fielden \\ UNITEC Institute of Technology, Auckland, New Zealand
}

kfielden@unitec.ac.nz

\begin{abstract}
This paper describes a qualitative participatory research project conducted at the National Advisory Committee on Computing Qualifications Conference in New Zealand (NACCQ2002). Data was gathered at a dynamic poster session. Results obtained indicated that majority of computing academics in the polytechnic community in New Zealand regard themselves as teaching in the core overlapping areas of Software Engineering, Computer Science and Information Systems, regardless of their professional affiliation. Most participants taught subjects that lay within the Information Systems area; very few positioned themselves in the exclusively Computer Science or Software Engineering areas, or in the ove rlap between Software Engineering and Computer. Results from this research are discussed in the paper.
\end{abstract}

Keywords: Information Technology, Tertiary Educators, Qualitative Research.

\section{Introduction}

This paper describes a qualitative participatory research project conducted at the National Advisory Committee on Computing Qualifications in New Zealand (NACCQ2002). Data was gathered at a dynamic poster session where participants represented their professional affiliations with a colored pin. Overlapping circles on the poster (figure 1) represented teaching areas in Information Technology.

75 out of 180 participants took part in this data-gathering exercise. A survey sheet was also gathered from 30 of the 75 participants. Results obtained from this research indicate that majority of computing academics in the polytechnic community in New Zealand regard themselves as teaching in the core overlapping areas of Software Engineering, Computer Science and Information Systems, regardless of their professional affiliation. Most participants taught subjects that lay within the Information Systems area and very few pos itioned themselves exclusively in the Computer Science or Software Engineering areas, or in the overlap between Software Engineering and Computer Sc ience.

Expected results were that this particular cohort of computing academics would position the mselves in all of the overlapping areas. Unexpectedly, few positioned themselves in the Software Engineering/ Computer Science overlap. Another unexpected result was the sense of community generated by participants who took part in the research. As the poster took shape, participants displayed a sense of ownership.

Material published as part of these proceedings, either on-line or in print, is copyrighted by Informing Science. Permission to make digital or paper copy of part or all of these works for personal or classroom use is granted without fee provided that the copies are not made or distributed for profit or commercial advantage AND that copies 1) bear this notice in full and 2) give the full citation on the first page. It is permissible to abstract these w orks so long as credit is given. To copy in all other cases or to republish or to post on a server or to redistribute to lists requires specific permission from the publisher at Publisher@InformingScience.org
In this paper, the terms Software Engineering, Computer Science and Information Systems are defined. Next, the local and global debate is explored. The paper continues with the research methodology, data gathering, analysis, interpretation as well as expected and emergent results. 


\section{Software Engineering, Computer Science \& Information Systems - Defining the Terms}

Software Engineering is defined as the application of a systematic, disciplined and quantifiable approach to the development, operation, and maintenance of software; that is, the application of engineering to software.

Computer Science is defined as a discipline that involves the understanding and design of computers and computational processes. In its most general form it is concerned with the understanding of information transfer and transformation. The discipline ranges theoretical studies of algorithms to practical problems of implementation in computational hardware and software. In Computer Science there is an inherent intermingling of the theoretical concepts of computability and algorithmic efficiency with the modern practical advancements in electronics that continue to stimulate advances in the discipline. It is this close interaction of the theoretical and design aspects of the field that binds them into a single discipline.

Information Systems is defined as the application of information to organizational needs. Information Systems is the study of information production, flows and use within organizations. Whilst Information Systems makes extensive use of information technology, it also encompasses systems in their entirety. This includes manual activities, the interface between manual and automated components of systems, design aspects of Information technology and economic, legal, organizational, behavioral and social aspects of systems.

It can be seen from the above definitions that the three disciplines overlap. For instance, Information Systems overlap with both Computer Science and Software Engineering in database management. Some aspects of application software development overlap with Computer Science, and systems analysis and organizational behavior overlap with the business-related disciplines.

Whilst each discipline area sets itself apart as it overlaps in content, the main distinguishing factor is the mindset adopted in the fields of Software Engineering, Computer Science and Information Systems. Software Engineering is positioned on a conceptual mindset landscape within engineering, encompassing all that can be managed, evaluated and measured according to the principles of the application of science.

Mindsets within Computer Science encompass innovation, ingenuity and scientific principles all aimed at harnessing and extending the power of electronics. In the mindset landscape of Info rmation Systems, practical applications of the inventions of Computer Science and the management and design principles of Software Engineering are applied to a myriad of problems, situations and environments in business, government, health, education and the community. Information Systems puts the theory and management principles to work in the world.

When we consider that polytechnics in New Zealand were established to provide higher education that could be applied directly to a working world, it is no wonder that computing staff within this sector regard themselves both as educators and practitioners in the larger arena of Information Systems.

\section{The Local and Global Debate}

'An increasing trend sees educators in cognate computing disciplines grouped in schools in Information Technology. '(Buchan, Clear, \& Hughes, 2002) They also maintain that Information Technology is an inherently murky term. Rather than seeing Information Technology as a murky term this paper takes an integrated approach to computing curriculum in polytechnic education in New Zealand.

Denning (2001) identifies over 40 Information Technology professional specialties, characterizing the $\mathrm{m}$ as IT-specific (Computer Science and Software Engineering) IT-intensive (such as E-commerce and MIS) and IT supportive (such as network technician and DBA). This is an industry professional point of 
view rather than a computing academic viewpoint. It is this latter point of view that is pursued in this paper. It is important to recognize that IT education needs span traditional boundaries of Computer Science, Software Engineering and Information Systems to provide a common core of capabilities and knowledge.

Orlikowski and Iacono (2001) nominate four different 'views' of IT - tool, computational, proxy (IT

Figure 1 Your Position as IT Professional

SE

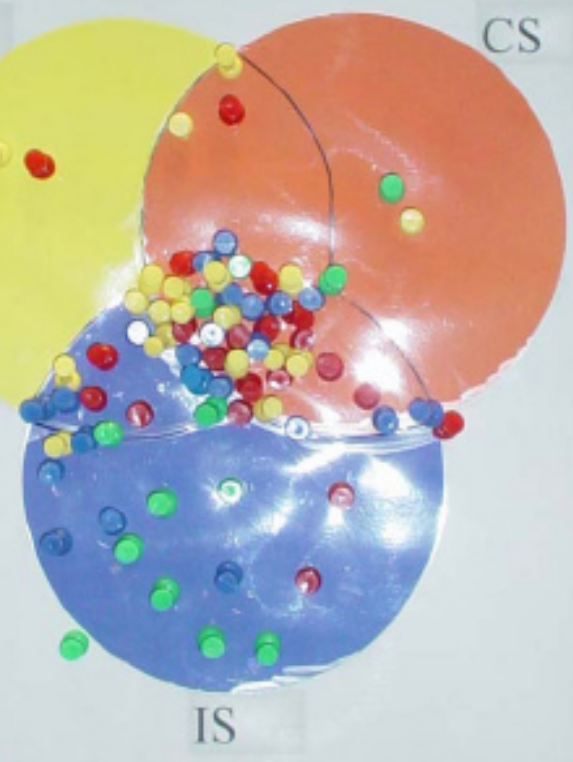
represented as a set of measures) and the ensemble view - IT as 'technology as development process'. These views of Information Technology cross the traditional discipline boundaries in this paper.

Buchan, Clear et al. (2002) conclude that it is important to address the 'chasm' that separates computing -- the discipline from the IT profession. Computing the discipline includes the design of interdisciplinary programs. Such programs need to be developed in alliance with industry partners. It is this point of view that is adopted in this paper.

\section{The Local Debate}

Some anticipated results not realized in this research pertain to positioning issues of computing departments. Traditionally in the university sector, Software Engineering, Computer Science and Information Systems are taught in different departments rather than a single computing department. It appears that this divide does not exist in the polytechnic sector. Included in their many certificate, diploma and degree offerings, Polytechnics in New Zealand provide the opportunity for students to gain practical knowledge in their chosen field, especially in computing.

\section{The Research Methodology}

This research grew collaboratively out of a series of seminars in which the Software Engineering, Computer Science and Information Systems debate was aired. The relative merits of integrated versus separate departments were discussed. Questions were posed on where New Ze aland polytechnics positioned themselves with their computing degrees; how computing academics viewed their particular discipline area; and if there was any common ground in computing.

The poster was designed in yet another seminar within the School of Computing and Information Technology. A collaborative workshop session with academic staff in the school established a design prototype for the poster.

Qualitative participatory research was adopted as the methodology of choice because it allowed for a variable and small number of responses, for informal convers ations to be included and for participants to be guided in their choice placement on the poster board (figure 1) and in decisions about curriculum areas taught. In qualitative participatory research, the researcher is the primary instrument of the research. In qualitative research and has an active and subjective part to play in the data gathe ring exe rcise.

The poster session was conducted over one day at the NACCQ2002 conference where the author facilitated the gathering of data. As conference delegates visited poster sites, they were invited to choose a colored pin - yellow for Software Engineering, red for Computer Science, blue for Information Systems and green for 'other'. The 'other ' pins were added as an after-thought when a visiting academic stated that she did not come from any of the computing discipline areas - she was a zoologist initially! It 
turned out that there were indeed a number of 'other' professions at the conference who were polytechnic educators in computing.

Once a delegate had chosen a colored pin, they were invited to place the pin on the poster in the area in which they taught. This was inevitably accompanied by a discussion about where a subject was on the diagram. On the poster site there was another diagram that delegates could consult if in any doubt (figure 2). As the day progressed it became clear that the core area in the ove rlapping circles of Software Engineering, Computer Science and Information Systems was becoming very crowded. On reflection it would have been better to allow a larger intersecting space on the poster.

There were also repeated visits from delegates who had participated earlier in the day. They were interested to view the changing picture displayed on the poster. Many theories were posited, and much debate ensued on reasons why the picture should be building the way it did. Those who participated in appeared to feel a sense of ownership of the poster - and those who did not take part had a sense of feeling left out of something important.

Participants were also asked if they would like to fill out a survey. Instructions for the survey were also on the poster site. It soon became clear that the collection of data needed to be facilitated, not just relying on instructions on the poster.

\section{Observed Patterns from the Poster}

Only 3 people positioned themselves teaching in a non-overlapping area in Software Engineering (Figure 3). Only two people in the non-overlapping Software Engineering area considered him/herself to be a Software Engineer (3\%) (Figure 3). One Computer Scientist was teaching in a non-overlapping area in Software Engineering (1.3\%). 7 out of 75 people positioned themselves outside of the Information Systems area (9.3\%) (SE+CS+CSSE areas, Figure 3). In other words 69 people considered their teaching area was in the Information Systems area (92\%) (SECSIS+IS+CSIS+SEIS, Figure 3). 36 out of 75 people positioned themselves as teaching in the core areas regardless of the discipline area $(47 \%)$ (SECSIS, Figure 3).

13 Software Engineers (17.3\%), 11 Computer Scientists (14.6\%), 10 Information Systems professionals (13.3) and 3 people (4\%) who came from another professional area taught in the core curriculum area. 3 people (4\%) only taught in the overlap area between Software Engineering and Computer Science - 2
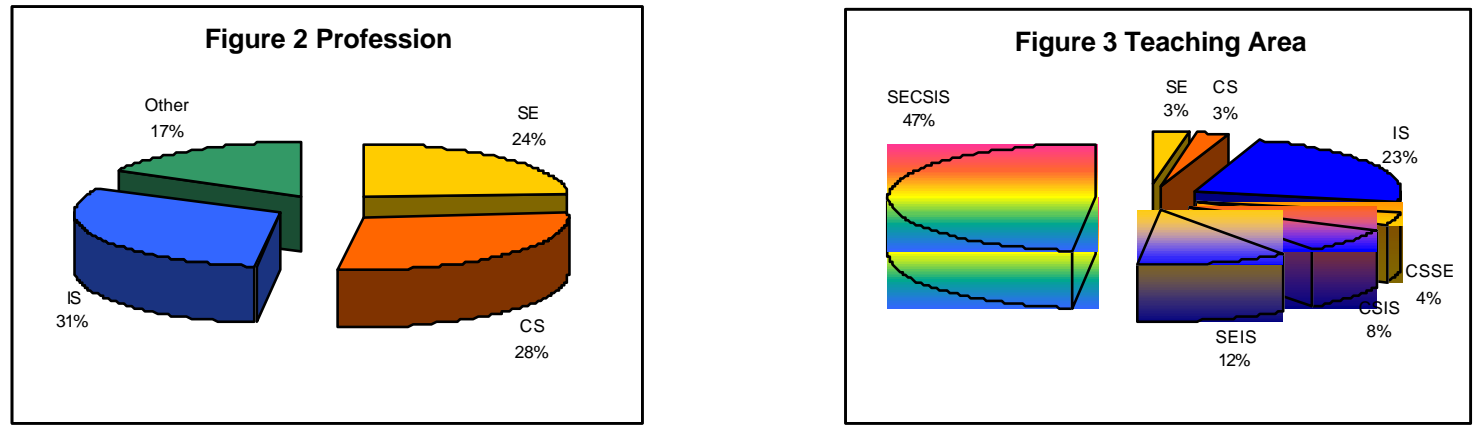

Software Engineers (3\%) and 1 Computer Scientist (1.3\%). 9 people (12\%) taught in the Software Engineering/Information Systems overlap area - 4 Information Systems professionals (6\%), 2 Software Engineers (3\%), 3 Computer Scientists (4\%) and 1 other (1.3\%) (Figure 3).

6 people (8\%) taught in the overlap area between Information Systems and Computer Science - 3 Computer Scientists (4\%) and 3 Information Systems professio nals (4\%). 2 people (3\%) only taught in just Computer Science - one Software Engineer (1.3\%) and one 'other' (1.3\%). 6 'other' people (8\%) 4 Information Systems professionals (6\%) and 2 Computer Scientists (3\%) taught in the Information Systems only area. 1'other' person was positioned outside the Information Systems area (1.3\%). 
When the poster (Figure 1) was analyzed, 18 people considered themselves to be Software Engineers, 21 Computer Scientists and 23 Information Systems professionals (Figure 2). The 13 'others' came from a wide variety of professional backgrounds including mathematics, zoology, communication, physics, history, chemistry, engineering and fine arts.

It can be seen from Figure 1 that the common ground is indeed Information Systems for this sector of computing academia in New Zealand. Regardless of professional background, $68 \%$ of participants had positioned the mselves in an overlap area with Information Systems. The common ground was, in the first instance the core overlap area with the three disciplines and in the second place with Information Systems/Software Engineering and Information Systems/ Computer Science.

\section{Survey Results}

$40 \%$ (30 out of 75) of those placing pins on the poster returned survey sheets by the end of the conference. It seems that this high response was due in part to the way in which the survey was carried out in a dynamic poster. A sense of community was demonstrated as participants discussed the relative merits of their professions, their teaching areas and how they came to be a computing academic. The sense of community also grew as participants took ownership of their colored pin. Some people revisited the poster many times to see how the picture was developing and who else had placed themselves alongside of them.

\section{Common Factors}

The results were analyzed to identify common ground rather than differentiating factors. As shown in Table 1, responses were divided evenly between viewing working with information technology and working with people as common factors in the three discipline areas ( 9 responses each). Eight people thought that working with tools, techniques and software development were the common factor in the three areas. Four viewed integrated knowledge, skills and experience were the common factors. Only two recognized the importance of best practice and planning as a common factor in the computing disciplines and one realized that all discipline areas require imagination and ingenuity.

Note: The discrepancies in number of responses in the following tables are because some respondents nominated more than one answer to each question. All such responses were included in the results. Whilst this is not strictly correct, statistically, it is important to remember that this is qualitative research.

\begin{tabular}{|l|c|}
\hline \multicolumn{1}{|c|}{ Common Factor } & Number \\
\hline Working with Information Technology & 9 \\
\hline Working with people, Business Information Systems & 9 \\
\hline Tools, techniques, Software development & 8 \\
\hline Integrated knowledge, skills and experience & 4 \\
\hline Best practice, planning & 2 \\
\hline Imagination and ingenuity & 1 \\
\hline Table 1: What do you see as the common factors on the three discipline areas? \\
\hline
\end{tabular}

\section{Differentiating Factors}

Factors that differentiate the three discipline areas (Table 2) from the 30 respondents present are more complex than the common factors (Table 1). 


\section{Where Do IT Staff Position Themselves}

Differentiating factors for Software Engineering included emphasis on project development, humancomputer interface, management, focus on end product and a belief that Software Engineering as more theory-focused.

Computer Science was seen as concentrating more on computer infrastructure, human-computer interface, algorithm and code, and more theory focused. Information Systems had a heavier emphasis on organizational and people aspects of computing and human-computer interface. One respondent in the Information Systems discipline area recognized that management, and analysis and design issues as being multi-disciplinary.

General responses given for differentiating factors included recognition of the level of abstraction and activity carried out in the three discipline areas. Four respondents commented on the areas of specialty in each area and specified what these might be.

These responses indicated that regardless of the individual's professional area, it appears that there was clarity on what the differentiating factors were in the three discipline areas.

\begin{tabular}{|c|c|c|c|}
\hline Software Engineering & Computer Science & Information Systems & General \\
\hline $\begin{array}{c}\text { Development } \\
\mathbf{6}\end{array}$ & $\begin{array}{l}\text { Computer Infrastructure } \\
\mathbf{1 0}\end{array}$ & $\begin{array}{c}\text { Organizations, People } \\
\mathbf{8}\end{array}$ & $\begin{array}{c}\text { Level of activity, } \\
\text { Abstraction } \\
7\end{array}$ \\
\hline $\begin{array}{c}\text { Human-Computer } \\
\text { Interaction } \\
\mathbf{3}\end{array}$ & $\begin{array}{l}\text { Human-Computer } \\
\text { Interaction } \\
\mathbf{1}\end{array}$ & $\begin{array}{c}\text { Human-Computer } \\
\text { Interaction - high level } \\
\mathbf{2}\end{array}$ & $\begin{array}{c}\text { Specialties } \\
\mathbf{4}\end{array}$ \\
\hline $\begin{array}{c}\text { Management } \\
\mathbf{4}\end{array}$ & $\begin{array}{c}\text { More Focus } \\
\mathbf{1}\end{array}$ & $\begin{array}{c}\text { Management, Systems } \\
\text { Analysis \& Design } \\
\mathbf{6}\end{array}$ & \\
\hline $\begin{array}{c}\text { End product } \\
\mathbf{1}\end{array}$ & $\underset{\mathbf{3}}{\text { Algorithm, Code }}$ & $\begin{array}{c}\text { Methodology } \\
\mathbf{2}\end{array}$ & \\
\hline \multirow[t]{2}{*}{$\begin{array}{l}\text { More Theory } \\
\mathbf{2}\end{array}$} & $\begin{array}{c}\text { More Theory } \\
\mathbf{3}\end{array}$ & $\begin{array}{l}\text { Multi-disciplinary } \\
\mathbf{1}\end{array}$ & \\
\hline & $\begin{array}{l}\text { Other } \\
\mathbf{2}\end{array}$ & & \\
\hline
\end{tabular}

When asked how they would differentiate themselves from the other two professions (Table 3), eight stated their chosen profession and their main interest; six suggested the difference lies in the level of detail; eight did not know or did not answer this question; four suggested the level of applicability made the difference; two were of the opinion that industry experienc e differentiated them; and three thought that usability was the point of difference.

Conclusions from this question remain unclear. While respondents could differentiate the discipline areas, they had much difficulty identifying their personal position. When the responses were grouped according to the discipline area (figure 1) the only people who felt they could not differentiate themselves were in the overlap areas. It was only those who taught in either Information Systems or Computer Science who could differentiate themselves from the other two professions. On reflection, this suggests that it is the common ground in computing that is recognized first, rather than the differentiating factors.

The main professional aim was seen as the delivery of quality software to businesses by ten participants; six believed the main aim was to improve skill levels; six others donned academic hats and decided that producing professional graduates was the most important aim; four combined professionalism and qua l- 
ity; three decided that the integration of the discipline areas was the main aim; and three gave no answers.

\begin{tabular}{lc|}
\hline \multicolumn{1}{c|}{ Differentiating Factor from Other Disciplines } & Number \\
\hline Main interest & 8 \\
\hline Level of detail & 6 \\
\hline I don't differentiate myself & 5 \\
\hline Applied Information Technology & 4 \\
\hline Useability & 3 \\
\hline No answer & 3 \\
\hline Industry Experience & 2 \\
\hline
\end{tabular}

\section{Table 3: How would you differentiate yourself from the other two professions?}

Only people placing themselves in the Information Systems circle (and this includes the overlap areas) identified themse lves as teachers within the profession whose main aim was to produce quality gradur ates. It is interesting to note that quality, improved skill, and professionalism were nominated by 26 of the respondents, regardless of the discipline area. These factors would appear to be important common ground.

\begin{tabular}{|lc|}
\hline \multicolumn{1}{c|}{ Main Aim in Your Professional Area } & Number \\
\hline Deliver quality software to business & 10 \\
\hline Improve skill levels & 6 \\
\hline Produce professional graduates & 6 \\
\hline Improve professionalism and quality & 4 \\
\hline Merge Software Engineering, Computer Science and Information Systems & 3 \\
\hline No Answer & 3 \\
\hline
\end{tabular}

Table 4: What would you see as the main aim in your professional field?

\section{Core Curriculum Areas in Your Discipline Area}

Figure 4 indicates core curriculum areas with programming and hardware considered to be the most important in the overlap of all three discipline-areas. Analysis, design and business process were considered core in the Information Systems only area. Software specification, design and implementation in the software/Information Systems overlap; operating systems in the Software Engineering/Computer Science overlap; and multimedia and the Internet in the Information Systems/Computer Science overlap. 


\section{Where Do IT Staff Position Themselves}

When the Computer Science/Software Engineering overlap is considered from figure 1, it is evident that there is a lack of academics actually teaching in this area. 7 people nominated operating systems as a core curriculum area but only 3 had placed a pin in this particular overlap area. There appears to be a similar shortage of academics in the Software Engineering sector with only two pins in this sector and

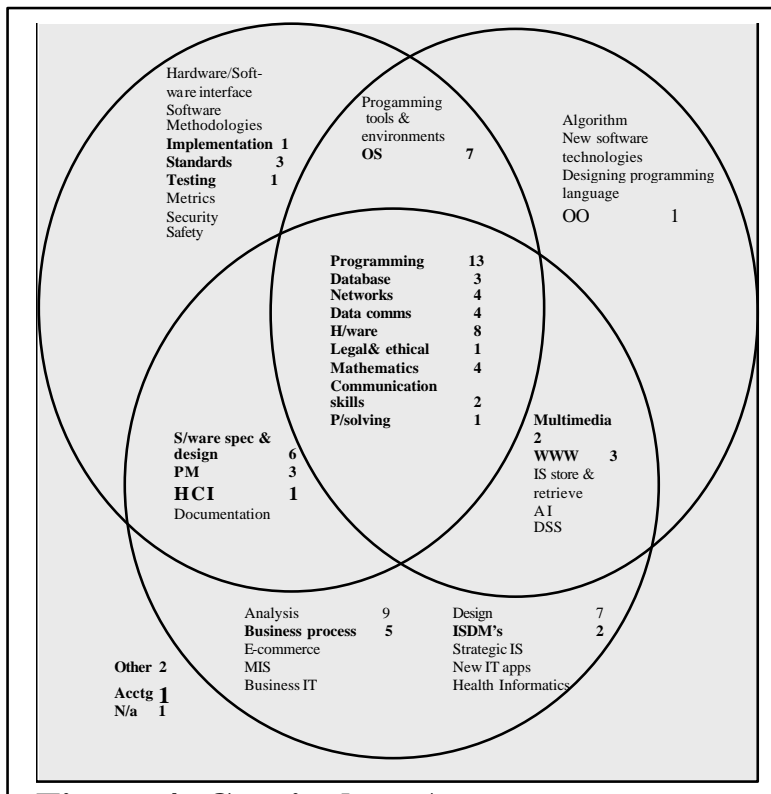

Figure 4: Curriculum Areas five nominating core curriculum topics in this area.

When asked to rank the importance of the three discipline areas (Table 5), 15 respondents decided that all areas were of equal importance; 5 ranked Information Systems first, Software Engineering second and Computer Science third; a nother 5 nominated Computer Science first, Software Engineering second and Information Systems third; four selected Information Systems first, Computer Sc ience second and Software Engineering third; only two chose Computer Science first, Information Systems second and Software Engineering third; one person nominated Information Systems only; and three did not respond.

Information Systems was first or equal choice for 25 out of 30 people; Software Engineering equal but not first choice for 15 people; and 17 nominated Computer Science equal but not first. When the pattern in figure 1 is studied, it can be seen that the 69 out of 75 placed themselves in the Information Systems area.

This supports the ranking from the survey. In this computing academic community, the ranking of Information Systems as equal or first is indeed the common ground.

\begin{tabular}{lc|}
\hline \multicolumn{1}{c}{ Ranking Order } & Number \\
\hline All areas ranked equal & 15 \\
\hline Information Systems $1^{\text {st }}$, Software Engineering $2^{\text {nd }}$, Computer Science $3^{\text {rd }}$ & 5 \\
\hline${\text { Computer Science } 1^{\text {st, }} \text { Software Engineering 2 }}^{\text {nd }}$, Information Systems $3^{\text {rd }}$ & 5 \\
\hline Information Systems $1^{\text {st }}$, Computer Science 2 ${ }^{\text {nd }}$, Software Engineering $3^{\text {rd }}$ & 4 \\
\hline Computer Science $1^{\text {st, }}$ Information Systems $2^{\text {nd }}$, Software Engineering $3^{\text {rd }}$ & 2 \\
\hline Information Systems & 1 \\
\hline Other & 2 \\
\hline No Answer & 3
\end{tabular}

\section{Table 5: How Do You Rank the Importance of the Three Discipline Areas?}

When asked which area was the most important input to industry (Table 6), 21 nominated Information Systems as first, equal or with another discipline area. From these combined responses it can be seen that the common ground of Information Systems emerged. 


\begin{tabular}{lcc|} 
& Area Most Important to Industry? & Number \\
\hline Information Systems & 14 \\
\hline All areas equal & 5 \\
\hline Software Engineering/Information Systems & 2 \\
\hline Software Engineering & 1 \\
\hline Computer Science & 1 \\
\hline Training graduates & 2 \\
\hline No Answer & 3 \\
\hline
\end{tabular}

Table 6: Which area do you regard as most important to industry?

\section{Implications}

This qualitative research with data gathered from a dynamic poster display and the survey has highlighted implications for curriculum design, alliance with industry, staff recruitment and retraining as well as the need for a solid curriculum in core topics in the polytechnic sector of higher education in New Zealand. It appears that there is a shortage of staff in the core curric ulum areas in the Computer Science/Software Engineering overlap area and the Software Engineering/Information Systems overlap area. It also appears that most participants are within the overlapping region and it is these participants that are most in demand in this sample.

\section{Curriculum Design}

These results indicate that the participants at this conference (National Advisory Committee on Computing Qualifications) saw the continuing need for a compulsory core of computing subjects. Participants saw themselves as capable of teaching in the core area regardless of original professional background. Integrated computing expertise that could be applied to industry was seen as more important than the more theoretical nature of pure Computer Science or Software Engineering. Conversations held with participants during the data gathering exercise indicated that students could limit their choices by opting for the "flavor of the month" computing topics in favor of necessary core topics which could limit their employment options.

\section{Alliances with Industry}

This sector of higher education in computing has active involvement with industry through industry advisory committees and capstone industry projects for undergraduate degrees, while regular reassessment of curriculum ensures its alignment with industry requirements. This was reinforced in conversations with participants.

\section{The Computing Common Ground}

Data gathered from the poster, the survey and from informal conversations with participants indicated that participants saw themselves as computing professionals first and members of a particular discipline area second. Even those people who had 'other' professional areas considered themselves to be computing academics. This was reinforced by the number of participants placing their teaching area within the core overlapping areas in figure 1 , by the number of survey responses seeing commonality before differentiation in the disciplines. 


\section{Conclusion}

This paper has described a qualitative participatory research project carried out at NACCQ2002 in which academics in the computing disciplines in the institutes of technology in New Zealand position themselves both within their chosen profession and their teaching area. The research was 'opportunistic' and participatory. Data was gathered from the poster, the survey and from informal discussions and observations made during the day. Not only did the research gather data from this particular set of computing professionals, but also the research added to the dynamic nature of the conference. The poster display was 'owned ' by all the participants, not just the researcher.

Results gained from this qualitative study are limited only to this particular sample of computing academics. Further research into the wider community of computing academia would add to the knowledge pool about where IT academics position themselves.

Results from the survey will be discussed at the next NACCQ conference in July 2003 and from there disseminated back into computing departments in the New Zealand polytechnic sector.

Common ground was discovered in the teaching curriculum areas in the core overlap between the three discipline areas of Software Engineering, Computer Science and Information Systems with most academics positioning themselves within the Information Systems area. Participants considered themselves to be computing professionals in academia rather than belonging to Software Engineering, Computer Science or Information Systems. It appears that this set of academics have an integrated worldview of computing with clear perspectives on core computing curriculum.

\section{References}

Buchan, J., Clear, T., \& Hughes, J. (2002). 'Computing the Profession': crossing the Chasm with a New Masters Degree in Information Technology. Technology and Innovations: New Understandings and Influences, NACCQ 2002, 21-28.

Denning, P. J. (2001). Who Are We? Communications of the ACM, 44(2), 15-19.

Orlikowski, W., \& Iacono, C. (2001). Research Commentary: Desperately Seeking the "IT" in IT Research - A Call to Theorizing the IT Artifact. Information Systems Research, 12(2), 121-134.

\section{Biography}

Kay Fielden holds a PhD and a Postgraduate Diploma in Social Ecology from the University of Western Sydney, Australia, an MSc in Computer Science from the University of New South Wales and a $\mathrm{BSc}$ (Hons) from Canterbury University, New Zealand. Currently she is research coordinator for the School of Computing and Information Technology at UNITEC Institute of Technology, Auckland, New Zealand and is responsible for both staff and postgraduate student research. 